\section{Remission in SLE: the duration depends on multiple factors, including the definition}

We read with great interest the article from Wilhelm et $a l^{1}$ published on Annals of the Rheumatic Diseases. We agree with the authors that remission is an emerging concept in systemic lupus erythematosus (SLE) and that it is very important to find out a definition of remission heralding the best outcome for clinical practice and clinical trials. Although this study, carried out in a very large monocentric cohort of lupus patients, is an important contribution to this topic, its result is a little bit disappointing: indeed, only a minority of lupus patients could maintain a durable remission, which means that, according to this study, remission is not a suitable target for SLE treatment. The percentage of patients with durable remission was so low that the authors did not analyse the effect of remission on disease outcomes such as damage accrual.

In our recent paper, ${ }^{2}$ we obtained very different results and our patients with durable remission achieved a better outcome compared with unremitted ones. Thus, before considering remission in SLE as a mistaken target, we should critically examine all our results.

Apart from the differences in ethnicity, clinical and serological features between the two cohorts, in Wilhelm's study the authors considered all patients who did not satisfy their definitions of remission at baseline and evaluated the time to the first remission and, thereafter, the time to the first flare. Thus, they evaluated only the first remission period per patient and not the longest period of remission over the follow-up, as we did in our study. This may be misleading since disease activity tends to be higher and the relapsing remitting course more common in the first years from the disease onset. ${ }^{3-8}$

However, the most important difference between the two studies lies in the definitions of remission and, particularly, the absence of physician global assessment (PGA) in the definitions we used. In Wilhelm's definitions of remission, patients must have both clinical Systemic Lupus Disease Activity Index (cSLEDAI) equal to 0 and PGA score $<0.5$ in order to be considered as remitted. Remarkably, approximately $40 \%$ of patients who did not satisfy the Wilhelm's definitions of remission at study entry had a cSLEDAI score equal to 0 and about $20 \%$ had a PGA score $<0.5$. Thus, the definitions of remission they used were more stringent than our definitions and a discrepancy between cSLEDAI and PGA score could have prevented the fulfilment of the definition of remission in their study.

Wilhelm's study is really very useful since it opens the discussion on a very important question: is it better a stringent definition of remission, only achieved by few patients, or a more liberal one associated with a decrease in damage progression? Thus, before considering disease remission a dead target in SLE treatment, we suggest caution in interpreting and reporting the results of the studies on remission in SLE.

\section{Andrea Doria, Margherita Zen, Luca laccarino}

Rheumatology Unit, Department of Medicine (DIMED), University of Padova, Padova, Italy

Correspondence to Professor Andrea Doria, Rheumatology Unit, Department of Medicine (DIMED), University of Padova, Padova 35128, Italy; adoria@unipd.it

Competing interests None declared.

Provenance and peer review Not commissioned; internally peer reviewed.



To cite Doria A, Zen M, laccarino L. Ann Rheum Dis 2016;75:e77.

Received 12 September 2016

Accepted 17 September 2016

Published Online First 5 October 2016

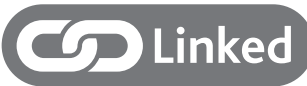

- http://dx.doi.org/10.1136/annrheumdis-2016-210564

Ann Rheum Dis 2016;75:e77. doi:10.1136/annrheumdis-2016-210502

\section{REFERENCES}

1 Wilhelm TR, Magder LS, Petri M. Remission in systemic lupus erythematosus: durable remission is rare. Ann Rheum Dis 2016; Published Online First 24 Aug 2016. doi: 10.1136/annrheumdis-2016-209489

2 Zen $M$, laccarino $L$, Gatto $M$, et al. Prolonged remission in Caucasian patients with SLE: prevalence and outcomes. Ann Rheum Dis 2015;74:2117-22.

3 Laustrup H, Voss A, Green A, et al. SLE disease patterns in a Danish population-based lupus cohort: an 8-year prospective study. Lupus 2010;19:239-46.

4 Urowitz MB, Gladman DD, Tom BD, et al. Changing patterns in mortality and disease outcomes for patients with systemic lupus erythematosus. I Rheumatol 2008;35:2152-8.

5 Urowitz MB, Gladman DD, Ibañez D, et al. Evolution of disease burden over five years in a multicenter inception systemic lupus erythematosus cohort. Arthritis Care Res (Hoboken) 2012;64:132-7.

6 Becker-Merok A, Nossent HC. Damage accumulation in systemic lupus erythematosus and its relation to disease activity and mortality. I Rheumatol 2006;33:1570-7.

7 Jonsson $\mathrm{H}$, Nived $\mathrm{O}$, Sturfelt G. Outcome in systemic lupus erythematosus: a prospective study of patients from a defined population. Medicine (Baltimore) 1989;68:141-50

8 Edwards $\mathrm{CJ}$, Lian TY, Badsha $\mathrm{H}$, et al. Hospitalization of individuals with systemic lupus erythematosus: characteristics and predictors of outcome. Lupus 2003:12:672-6. 